\title{
Bilateral Asymmetry of Cross-sectional Radiogrametric and Microdensitometric Measurements in the Second Metacarpal*
}

\author{
By
}

\author{
Kunihiko KIMURA \\ Department of Anatomy, National Defense Medical College \\ Namiki 3-2, Tokorozawa, Saitama 359, Japan.
}

- Received for Publication, June 20, 1989-

\begin{abstract}
Key words: Asymmetry, Radiogrametry, Microdensitometry, Cross-sectional geometry, Second metacarpal
Summary: On the basis of radiographs of the midshaft cross-section of the second metacarpal in 102 male and 96 female Japanese, aged 30-98 years, side-related differences of radiogrametric, biomechanical and microdensitometric parameters are examined. The bone section is more or less elliptical, and the major axis tilts somewhat radially from the median line at its dorsal end. Significant correlations are found between the right and left hands for each parameter at $p \leqq 0.01$. Bone size (BW and BA) and the relative magnitude of bending rigidity of a section (Imax and Imin) are significantly or arithmetically greater in the right hand than in the left. However, the cortical mass relative to the bone (MCI and $\mathrm{CA} / \mathrm{BA}$ ), biomechanical shape index (Imax/Imin and BWmax/BWmin) and total, mean and true bone density (TPA, MBD and MPH) are nearly identical in both hands. The cortical thickness and total mean bone density is significantly greater in the dorsovolar direction than in the radioulnar, and on the ulnar side than on the radial and on the volar side than on the dorsal. but the true bone density does not show such differences.
\end{abstract}

Bone density is a relative content of bony tissue (Nordon, 1987). It has been evaluated by numerous methods. Most of the methods are based on photometry of $\mathrm{x}$-ray films. The simplest quantitative technique is the measurement of the cortical thickness of bones (radiogrametry). Recently, radiogrametric microdensitometry (MD method) also has become one of the most widely used techniques for assessing bone mass in diagnosis of osteoporosis because of its comparatively low cost. These radiogrametric values of bones in vivo include some errors due to various reasons. The measurement is strictly limited to those sites which are readily accessible, where the bony contour is most uniform and where large individual variations in soft tissue coverage do not occur. The shafts of the humerus, radius, metacarpal, femur and tibia have been used most frequently for the quantitative measurement of bone mineral in vivo (Barnett and Nordin, 1960; Virtama and Mähönen, 1960; Meema, 1963), and these measurements provide useful information for clinical purposes (Aitken, et al., 1974; Savile, et al., 1976; Laval-Jeantet, et al., 1977; Bloome, 1980). The second metacarpal is comparatively easy to treat for the study because of its small size and its being a model of a long bone with a cylindric shaft. Long bone cross-sectional geometry could give not only more exact information for bone mass but also biomechanically simple quantitative expression to complex functional relationships, as studied for the tibia and fibula (Kimura, 1974) and the femur and tibia (Ruff and Hayes, 1983 ${ }^{1,2}$ ), though it is impossible in vivo. Side-related differences have been studied on compact cortical bone geometry (Virtama and Helelä, 1969; Adams, et al., 1970; Dequeker, 1972, 1976; Montoye, et al., 1976; Horsman, et al., 1981), considering handedness (Watson, 1973; Garn, et al., 1976; Plato, Wood, et al., 1980; Kimura and Konishi, 1981; Plato and Purifoy, 1982), activity (Plato and Norris, 1980) and mechanical loadings on each side (Ruff and Jones, 1981; Ruff and Hayes, $1983^{2}$ )

The present study examines side-related differences of main radiogrametric, biomechanical and microdensitometric parameters in the midshaft cross-section of the second metacarpal in Japanese.

\section{Materials and Methods}

The second metacarpals of both hands were obtained from 198 Japanese cadavers during dissection by students between 1980 and 1988 . The specimens comprise 102 males $(\bar{x}=62.8$ yrs., $S D=14.87)$ and 96 females $(\bar{x}=75.4$ yrs., $S D=12.85)$, aged 32 to 98 years. Although the donor's registration forms and death 
certificates were available, full personal records including; for example, their occupation, economic situation, handedness, etc. were not necessarily known for each specimen. Those individuals who had died of a disease involving osteoporosis, such as Basedow's disease, Werner's syndrome, rheumarthritis, diabetes, renal failure, etc., were excluded insofar as possible from the study.

Each cadaver had been injected with $10 \%$ formalin through the femoral artery and preserved for one year at least in a bag containing a small amount of $10 \%$ formalin and pure alcohol solution. After removal of the soft tissues from the bone as completely as possible, a section a little more than $2 \mathrm{~mm}$ thick was cut out at midshaft horizontally to the longitudinal axis using a low speed diamond bladed circular saw (Buehler Isomet, U.S.A.). The section was ground down to exactly $2 \mathrm{~mm}$ thickness using fine waterproof sandpaper. After washing with distilled water, using a transsonic irrigator (Elma T780, West Germany) for 2 hours, and air-drying it, the section was radiographed (Fuji FR $\mathrm{X}$-ray films, Japan) with an anode-film distance of $76 \mathrm{~cm}$ in the proximo-distal projection, using a standard radiographic technique $(45 \mathrm{kV}, 3.0 \mathrm{mAs}$ and $120 \mathrm{sec})$ with the Softex-C-MS system (Softex, Japan), together with an A1 step wedge. The wedge is placed as closely as possible and parallel to the shaft of the bone. It consists of 10 steps varying from $0.5 \mathrm{~mm}$ to $5.0 \mathrm{~mm}$ of a homogenous alloy of $99.9 \% \mathrm{Al}$ and $0.1 \%$ others, and each step has an area $10 \mathrm{~mm} \times 10 \mathrm{~mm}$.

Parameters. In the present paper, the median plane of the section passes through the center and a blunt crest on the volar surface of the bone. On the x-ray films (Plate 1), subperiosteal diameter (BW) and medullary width (MW) in both radioulnar (ru) and dorsovolar (dv) directions and cortical thickness (CT) at each radial, ulnar, dorsal and volar side were measured with the Professional Digitizer AC-30 (Mutoh Ltd, Japan). From these measurements, the combined cortical thickness (CCT) and metacarpal cortical index $(\mathrm{MCI}=\mathrm{CCT} / \mathrm{BW})$ were calculated.

At the same time, on photographs (Fujibro WP FM, Japan) of the x-ray films enlarged 11 times, subperiosteal and smooth endosteal boundaries were manually traced with a stylus on the digitizer so as to measure the total bone and medullary areas (BA and $\mathrm{MA})$. The cortical area $(\mathrm{CA}=\mathrm{BA}-\mathrm{MA})$ was calculated from them. After placing a thin plate with a $5 \mathrm{~mm}$ mesh on each photograph, maximum and minimum second moments of area (Imax and Imin) are calculated with the digitizer by $\mathrm{I}_{\mathrm{z}}=\Sigma_{\mathrm{A}} \mathrm{y}^{2} \mathrm{dA}$ (y: distance from $\mathrm{z}$ ). The orientation of principal axis $(\theta)$ is measured here anticlockwise from the $\mathrm{x}$ axis to the major axis. CA may be an appropriate dimension for evaluating internal resistance to pure axial loads in the foot. Imax and Imin indicate the relative magnitudes of greatest and least bending rigidity of a section, respectively, and $\theta$ defines the directions of greatest and least bending rigidity. The Imax/Imin ratio (Imax/ min) may be a kind of biomechanical shape index (Jungers and Minns, 1979), like the BWmax/BWmin ratio $(\mathrm{BWmax} / \mathrm{min})$.

Next, using the $0.1 \mathrm{~mm}$ diameter spot beam, data were scanned by a laser densitometer (LKB 2222-020 UltraScan, Sweden) at $0.04 \mathrm{~mm}$ intervals along the wedge image longitudinally and across the bone image in the radioulnar and dorsovolar directions on the films. The results were computed automatically into $\mathrm{mm}$ standardized Al equivalent values (SAE). Two microdensitometric (MD) cross-sectional bone patterns in SAE were obtained in the radioulnar and dorsovolar directions for each specimen (Plate 1). Each MD pattern comprises two curves corresponding to the radial and ulnar/the dorsal and volar cortices and an intermediate zero line to the medullary cavity of the bone crosssection. From the ru and dv MD patterns, four pattern areas (PA) and four peak heights $(\mathrm{PH})$ were measured with the digitizer at radial, ulnar, dorsal and volar sides. From these measurements, total pattern areas $(\mathrm{TPA}=\mathrm{PA}+\mathrm{PA})$ and mean peak heights $(\mathrm{MPH}=$ $[\mathrm{PH}+\mathrm{PH}] / 2$ ) were calculated on each MD pattern. TPA corresponds to the absolute total bone density (TBD) and MPH to the maximum or true bone density (MaxBD). In order to compare bone mineral content in different individuals, a kind of standardization of skeletal size was carried out, such as simply dividing PA and TPA by the bone width (BW) across the path of the scan, that is, the standardized or relative bone density $(\mathrm{BD}=\mathrm{PA} / \mathrm{BW})$ and mean bone density $(\mathrm{MBD}=\mathrm{TPA} / \mathrm{BW})$, on each MD pattern.

\section{Results}

Tables 1 and 2 present means and standard deviations of midshaft cross-sectional radiogrametric, biomechanical and microdensitometric measurements of the left and right second metacarpals in each sex, respectively. As shown in Table 3, significant correlations are found between the left and right hands at $\mathrm{p} \leqq 0.01$ for each parameter.

In radiogrametric and biomechanical parameters, significant side-related differences are found in BWru, $\mathrm{BA}$, Imax and Imin at $\mathrm{p} \leqq 0.01$ or 0.05 based on the paired t-test, but are not found in CCTru, CTr, MCIru, MWdv, CTd, MCIdv, CA/BA, $\theta$, Imax/ Imin and $\mathrm{BWmax} / \mathrm{BWmin}$, in common to both sexes. For example, in some parameters, frequencies of the balanced $(\mathrm{d}= \pm 0.2 \mathrm{SD})$, right dominant $(\mathrm{R}>\mathrm{L})$ and left dominant $(\mathrm{R}<\mathrm{L})$ specimens are as follows: 
Table 1. Means and standard deviations of radiogrametric and biomechanical measurements of the second metacarpal at midshaft cross-section in 102 males and 96 females.

\begin{tabular}{|c|c|c|c|c|c|c|c|c|c|c|}
\hline & \multicolumn{4}{|c|}{ Males } & & \multicolumn{4}{|c|}{ Females } & \multirow{3}{*}{$\mathrm{d}$} \\
\hline & \multicolumn{2}{|c|}{ Right } & \multicolumn{2}{|c|}{$\overline{\text { Left }}$} & & \multicolumn{2}{|c|}{ Right } & \multicolumn{2}{|c|}{ Left } & \\
\hline & $\bar{x}$ & $\mathrm{SD}$ & $\overline{\mathrm{x}}$ & $\mathrm{SD}$ & & $\overline{\bar{x}}$ & $\mathrm{SD}$ & $\bar{x}$ & $\overline{\mathrm{SD}}$ & \\
\hline BWru & 8.2 & 0.61 & 8.0 & 0.61 & $* *$ & 7.4 & 0.63 & 7.3 & 0.59 & $*$ \\
\hline MWru & 4.2 & 0.77 & 4.1 & 0.79 & *- & 4.6 & 0.84 & 4.6 & 0.78 & \\
\hline CCTru & 3.9 & 0.61 & 3.9 & 0.63 & & 2.8 & 0.75 & 2.7 & 0.71 & \\
\hline CTr & 1.9 & 0.35 & 1.9 & 0.36 & & 1.3 & 0.38 & 1.3 & 0.34 & \\
\hline CTu & 2.0 & 0.32 & 2.0 & 0.34 & & 1.5 & 0.42 & 1.4 & 0.42 & $*$ \\
\hline MCIru & 0.5 & 0.08 & 0.5 & 0.08 & & 0.4 & 0.10 & 0.4 & 0.09 & \\
\hline$B W d v$ & 9.2 & 0.69 & 9.2 & 0.67 & & 8.4 & 0.64 & 8.3 & 0.64 & $* *$ \\
\hline MWdv & 4.8 & 0.86 & 4.7 & 0.87 & & 5.5 & 0.93 & 5.5 & 0.86 & \\
\hline CCTdv & 4.4 & 0.71 & 4.4 & 0.76 & & 2.9 & 0.81 & 2.8 & 0.73 & $*$ \\
\hline CTd & 2.1 & 0.42 & 2.1 & 0.45 & & 1.3 & 0.37 & 1.3 & 0.39 & \\
\hline CTV & 2.4 & 0.41 & 2.3 & 0.40 & & 1.6 & 0.47 & 1.5 & 0.41 & $* *$ \\
\hline MCIdv & 0.5 & 0.08 & 0.5 & 0.08 & & 0.3 & 0.09 & 0.3 & 0.09 & \\
\hline $\mathrm{BA}$ & 60.5 & 7.43 & 58.5 & 6.94 & $* *$ & 48.7 & 6.33 & 47.1 & 5.72 & $* *$ \\
\hline MA & 16.2 & 5.34 & 15.6 & 5.07 & *- & 19.9 & 6.35 & 19.4 & 5.52 & \\
\hline $\mathrm{CA}$ & 44.3 & 5.86 & 43.0 & 5.65 & $* *$ & 28.8 & 6.18 & 27.7 & 5.83 & \\
\hline $\mathrm{CA} / \mathrm{BA}$ & 0.7 & 0.07 & 0.7 & 0.07 & & 0.6 & 0.10 & 0.6 & 0.10 & \\
\hline $\operatorname{Imax}$ & 268.5 & 72.52 & 248.7 & 60.48 & $* *$ & 153.8 & 44.28 & 142.0 & 40.78 & ** \\
\hline Imin & 185.6 & 53.22 & 172.6 & 46.75 & $* *$ & 110.1 & 32.49 & 104.5 & 30.08 & ** \\
\hline$\theta$ & 108.0 & 25.24 & 105.8 & 20.18 & & 96.0 & 25.05 & 98.3 & 24.51 & \\
\hline $\operatorname{Imax} / \operatorname{Imin}$ & 1.5 & 0.23 & 1.5 & 0.24 & & 1.4 & 0.25 & 1.4 & 0.25 & \\
\hline $\mathrm{BW} \max / \mathrm{BW}$ Min & 1.2 & 0.08 & 1.2 & 0.08 & & 1.2 & 0.08 & 1.2 & 0.08 & \\
\hline
\end{tabular}

$\mathrm{BW}, \mathrm{MW}, \mathrm{CCT}$ and $\mathrm{CT}$ in $\mathrm{mm}, \mathrm{BA}, \mathrm{MA}$ and CA in $\mathrm{mm}^{2}$, Imax and $\mathrm{Imin}$ in $\mathrm{mm}^{4}$, and $\theta$ in degrees. The marks *- and ${ }^{* *}$ show significant side-differences at $\mathrm{P} \leqq 0.05$ and $\mathrm{p} \leqq 0.01$, respectively.

Table 2. Means and standard deviations of microdensitometric measurements of the second metacarpal at midshaft cross-section in 102 males and 96 females.

\begin{tabular}{|c|c|c|c|c|c|c|c|c|c|}
\hline & \multicolumn{4}{|c|}{ Males } & \multicolumn{4}{|c|}{ Females } & \multirow{3}{*}{$\mathrm{d}$} \\
\hline & \multicolumn{2}{|c|}{ Right } & \multicolumn{2}{|c|}{ Left } & \multicolumn{2}{|c|}{ Right } & \multicolumn{2}{|c|}{ Left } & \\
\hline & $\bar{x}$ & $\overline{\mathrm{SD}}$ & $\overline{\mathrm{x}}$ & $\overline{\mathrm{SD}}$ & $\overline{\mathrm{x}}$ & $\overline{\mathrm{SD}}$ & $\bar{x}$ & $\mathrm{SD}$ & \\
\hline PAr & 92.1 & 21.11 & 89.1 & 21.58 & 51.0 & 18.09 & 49.0 & 16.97 & \\
\hline $\mathrm{PAu}$ & 97.8 & 20.96 & 99.5 & 21.61 & 58.6 & 21.54 & 56.6 & 20.51 & \\
\hline PAd & 94.8 & 21.99 & 97.0 & 25.53 & 50.7 & 18.93 & 48.5 & 16.61 & \\
\hline PAv & 116.5 & 26.51 & 117.7 & 26.60 & 70.2 & 30.00 & 64.1 & 21.53 & \\
\hline TPAru & 189.8 & 40.03 & 188.6 & 40.91 & 109.7 & 38.56 & 105.6 & 35.91 & $*$ \\
\hline TPAdv & 211.4 & 45.10 & 214.6 & 49.15 & 120.9 & 47.21 & 112.3 & 36.50 & ** \\
\hline $\mathrm{BDr}$ & 11.1 & 2.68 & 11.1 & 2.80 & 6.9 & 2.39 & 6.8 & 2.31 & \\
\hline $\mathrm{BDu}$ & 11.8 & 2.68 & 12.3 & $2.77 * *$ & 7.9 & 2.88 & 7.9 & 2.82 & \\
\hline BDd & 10.2 & 2.52 & 10.5 & 2.85 & 6.0 & 2.25 & 5.9 & 1.96 & \\
\hline $\mathrm{BDv}$ & 12.6 & 3.14 & 12.8 & 3.12 & 8.3 & 3.49 & 7.7 & 2.57 & ** \\
\hline MBDru & 22.9 & 5.15 & 23.4 & 5.30 & 14.8 & 5.12 & 14.7 & 4.89 & \\
\hline MBDdv & 22.8 & 5.31 & 23.3 & 5.65 & 14.3 & 5.55 & 13.6 & 4.34 & $*$ \\
\hline $\mathrm{PHr}$ & 2.0 & 0.11 & 2.0 & 0.12 & 1.7 & 0.25 & 1.7 & 0.24 & \\
\hline $\mathrm{PHu}$ & 2.1 & 0.12 & 2.1 & 0.10 & 1.7 & 0.25 & 1.7 & 0.25 & \\
\hline $\mathrm{PHd}$ & 2.1 & 0.10 & 2.1 & 0.12 & 1.7 & 0.25 & 1.7 & 0.25 & \\
\hline $\mathrm{PHV}$ & 2.0 & 0.11 & 2.0 & 0.11 & 1.7 & 0.25 & 1.7 & 0.25 & \\
\hline MPHru & 2.0 & 0.11 & 2.0 & 0.11 & 1.7 & 0.25 & 1.7 & 0.25 & \\
\hline MPHdv & 2.0 & 0.10 & 2.0 & 0.11 & 1.7 & 0.25 & 1.7 & 0.25 & \\
\hline
\end{tabular}

The marks * and ** show significant side-differences at $\mathrm{P} \leqq 0.05$ and $\mathrm{p} \leqq 0.01$, respectively. 
Table 3. Correlation coefficients of all parameters between both hands.

\begin{tabular}{llllll}
\hline & Males & Females & & Males & Females \\
\hline BWru & $0.80^{* *}$ & $0.76^{* *}$ & BWdv & $0.84^{* *}$ & $0.80^{* *}$ \\
MWru & $0.81^{* *}$ & $0.84^{* *}$ & MWdv & $0.88^{* *}$ & $0.86^{* *}$ \\
CCTru & $0.81^{* *}$ & $0.88^{* *}$ & CCTdv & $0.80^{* *}$ & $0.82^{* *}$ \\
MCIru & $0.81^{* *}$ & $0.88^{* *}$ & MCIdv & $0.84^{* *}$ & $0.84^{* *}$ \\
\hline TA & $0.90^{* *}$ & $0.89^{* *}$ & Imax & $0.86^{* *}$ & $0.88^{* *}$ \\
MA & $0.85^{* *}$ & $0.85^{* *}$ & Imin & $0.87^{* *}$ & $0.84^{* *}$ \\
CA & $0.85^{* *}$ & $0.87^{* *}$ & Imax/Imin & $0.58^{* *}$ & $0.61^{* *}$ \\
CA TA & $0.82^{* *}$ & $0.84^{* *}$ & $\theta$ & $0.52^{* *}$ & $0.33^{* *}$ \\
\hline TPAru & $0.80^{* *}$ & $0.88^{* *}$ & TPAdv & $0.80^{* *}$ & $0.87^{* *}$ \\
MBDru & $0.92^{* *}$ & $0.89^{* *}$ & MBDdv & $0.84^{* *}$ & $0.87^{* *}$ \\
MCDru & $0.93^{* *}$ & $0.83^{* *}$ & MCDdv & $0.92^{* *}$ & $0.81^{* *}$ \\
MPHru & $0.92^{* *}$ & $0.98^{* *}$ & MPHdv & $0.94^{* *}$ & $0.98^{* *}$ \\
\hline
\end{tabular}

Significant levels at $\mathrm{p} \leqq 0.01\left(^{* *}\right)$ and $0.05\left({ }^{*-}\right)$

\begin{tabular}{|c|c|c|c|c|c|c|}
\hline & \multicolumn{3}{|c|}{ Males } & \multicolumn{3}{|c|}{ Females } \\
\hline & $\mathrm{R}>\mathrm{L}$ & $\mathrm{R}=\mathrm{L}$ & $\mathrm{R}<\mathrm{L}$ & $\mathrm{R}>\mathrm{L}$ & $\mathrm{R}=\mathrm{L}$ & $\mathrm{R}<\mathrm{L}$ \\
\hline $\mathrm{BA}$ & 65.7 & 23.5 & 10.8 & 66.7 & 15.6 & 17.7 \\
\hline $\mathrm{CA}$ & 61.8 & 9.8 & 28.4 & 54.2 & 16.7 & 29.1 \\
\hline Imax & 69.6 & 5.9 & 24.5 & 65.5 & 14.6 & 19.8 \\
\hline $\mathrm{CA} / \mathrm{CB}$ & 42.2 & 12.7 & 45.1 & 38.5 & 21.9 & 39.6 \\
\hline
\end{tabular}

In general, the right dominant specimen occurs more frequently than the left dominant and the balanced in bone mass and biomechanical bending rigidity, but there are few differences in frequencies of the right and left dominant specimens in biomechanical bone shape.

Table 4 gives correlation coefficients of the side difference (R-L) of radiogrametric parameters with the biomechanical parameters (Imax, Imin and $\theta$ ) in each hand. Significant correlations are found in some relationships. As shown in gothic type in the table, in common to both sexes, it is noted that the side difference of TA correlates significantly with Imax and Imin only in the right hand. And also, the side difference of CA tends to correlate with Imax and Imin positively in the right hand but negatively in the left.

Significant correlations are found between the radioulnar and dorsovolar values of each parameter (0.60-0.85, except $0.28-0.36$ in $\mathrm{BW})$, and in each pair of CTs at four sides $(0.43-0.80)$ at $\leqq 0.01$ in both sexes. The dorsovolar value is significantly greater than the

Table 4. Correlation coefficients between the side differences of radiogrametric parameters (R-L) and biomechanical parameters (Imax, Imin and $\theta$ ) in the right and left hands.

\begin{tabular}{|c|c|c|c|c|c|c|c|}
\hline \multirow[b]{2}{*}{$\mathrm{R}-\mathrm{L}$} & \multirow[b]{2}{*}{ Sex } & \multicolumn{2}{|c|}{$\operatorname{Imax}$} & \multicolumn{2}{|c|}{ Imin } & \multicolumn{2}{|c|}{$\theta$} \\
\hline & & $\mathrm{R}$ & $\mathrm{L}$ & $\mathrm{R}$ & $\mathrm{L}$ & $\mathrm{R}$ & $\mathrm{L}$ \\
\hline \multirow[t]{2}{*}{ BWru } & $\hat{\delta}$ & 0.06 & 0.02 & 0.17 & -0.12 & $0.20^{*}-$ & 0.15 \\
\hline & 우 & 0.05 & -0.04 & $0.24^{* *}$ & -0.10 & -0.05 & -0.36 ** \\
\hline \multirow[t]{2}{*}{$\mathrm{BWdv}$} & $\hat{\jmath}$ & 0.09 & -0.15 & 0.12 & 0.01 & -0.18 & 0.12 \\
\hline & q & 0.18 & -0.08 & 0.07 & -0.04 & -0.10 & 0.06 \\
\hline \multirow[t]{2}{*}{ MWru } & $\hat{\delta}$ & 0.04 & 0.05 & 0.09 & -0.11 & 0.17 & 0.16 \\
\hline & i & -0.02 & -0.10 & 0.18 & -0.04 & -0.00 & $-0.24^{*}$ \\
\hline \multirow[t]{2}{*}{$M W d v$} & $\hat{\delta}$ & $0.20^{*}$ & 0.14 & 0.10 & 0.06 & 0.08 & 0.13 \\
\hline & q & 0.14 & 0.06 & 0.11 & 0.08 & 0.08 & 0.07 \\
\hline \multirow[t]{2}{*}{ CCTru } & $\hat{\delta}$ & 0.01 & -0.04 & 0.04 & -0.02 & -0.02 & -0.06 \\
\hline & q & 0.09 & 0.09 & 0.04 & -0.07 & -0.07 & -0.11 \\
\hline \multirow[t]{2}{*}{ CCTdv } & $\hat{\jmath}$ & -0.11 & -0.24 & 0.01 & -0.04 & $-0.21^{*-}$ & -0.03 \\
\hline & iq & 0.02 & -0.13 & -0.05 & -0.12 & -0.17 & 0.14 \\
\hline \multirow[t]{2}{*}{ BA } & $\hat{\delta}$ & $0.30^{\star \star}$ & -0.01 & $0.29^{\star *}$ & -0.04 & 0.11 & 0.13 \\
\hline & ㅇ & $0.36^{\star *}$ & -0.00 & $0.41^{\star *}$ & -0.00 & 0.06 & -0.14 \\
\hline \multirow[t]{2}{*}{$\mathrm{MA}$} & $\hat{\delta}$ & 0.12 & 0.06 & 0.12 & 0.00 & $0.19^{*-}$ & 0.13 \\
\hline & q & 0.14 & 0.12 & $0.23^{* *}$ & 0.18 & 0.09 & 0.14 \\
\hline \multirow[t]{2}{*}{$\mathrm{CA}$} & $\hat{3}$ & 0.17 & -0.07 & 0.17 & -0.04 & -0.08 & 0.00 \\
\hline & q. & 0.18 & -0.13 & 0.14 & 0.19 & 0.04 & 0.01 \\
\hline
\end{tabular}

Significant levels at $\mathrm{p} \leqq 0.01\left(^{* *}\right)$ and $0.05(*-)$. Figures in bold letters, wo parameters possibly show an inverse correlation each other in the right and left hands. 
radioulnar in almost all radiogrametric parameters at $\mathrm{p} \leqq 0.01$ or 0.05 in both sexes, with an exception for MCI. CT is significantly or arithmetically greater in the orders of $\mathrm{CTv}>\mathrm{CTd}>\mathrm{CTu}>\mathrm{CTr}$ in males and of $\mathrm{CTv}>\mathrm{CTu}>\mathrm{CTd}=\mathrm{CTr}$ in females. At least, $\mathrm{CTu}$ is greater than $\mathrm{CTr}$, and CTv is greater than CTd, significantly at $\mathrm{p} \leqq 0.01$ in both sexes.

However, no side-related differences are found in common to both sexes for all microdensitometric parameters. The mean values are greater in the right hand than in the left for TPAru, TPAdv, BDv and MBDdv in females, but in the left hand than in the right for BDu in males. Significant correlations are found between the radioulnar and dorsovolar values of each parameter (0.84-0.99) and in each pair of PAs, BDs and $\mathrm{PHs}$ at four sides $(0.72-0.99)$ at $\mathrm{p} \leqq 0.01$ in both sexes. Although TPAdv is significantly greater than TPAru at $\mathrm{p} \leqq 0.01, \mathrm{MBD}$ and MPH are almost similar between radioulnar and dorsovolar directions, in both sexes. PA is significantly or arithmetically greater in the orders of $\mathrm{APv}>\mathrm{PAu}>\mathrm{PAd}>\mathrm{PAr}$ in males and of PAv $>$ $\mathrm{PAu}>\mathrm{PAr}>\mathrm{PAd}$ in famales, and $\mathrm{BD}$ in the order of $\mathrm{BDv}>\mathrm{BDu}>\mathrm{BDr}>\mathrm{BDd}$ in both sexes. At least, in $\mathrm{PA}$ and $\mathrm{BD}$, the ulnar value is greater than the radial, and the volar value is greater than the dorsal, significantly at $\mathrm{p} \leqq 0.01$ in both sexes. However, there are no significant differences in PHs at four sides.

\section{Discussions}

It is now well established that bone loss occurs with age in most normal persons and that its onset is earlier in females than in males. It is also confirmed in this series (Kimura, Konishi, et al., 1989). The difference between the hands in the rate of decrease of the metacarpal bone mass was not significant (Horsman, et al., 1981). There were no significant correlations $(r=-0.14$ to 0.17 ) between the side differences and ages for all parameters in both sexes of this series. Therefore, it should be possible to discuss side differences of the second metacarpal based on the present specimens aged 30 to 98 years in each sex.

In this series, significant correlations are found between the left and right hands for each parameter. However, all parameters are significantly greater in one hand than in the other at $\mathrm{p} \leqq 0.01$. Bone size (BW and $\mathrm{BA})$ and the relative magnitude of bending rigidity of a section (Imax and Imin) are significantly or arithmetically greater in the right hand than in the left. The right dominant $(\mathrm{R}>\mathrm{L})$ specimen occurs more frequently than the left dominant $(\mathrm{R}<\mathrm{L})$ and the balanced $(\mathrm{R}=\mathrm{L})$ in such a parameter. This fact has been observed by many investigators (Virtama and Helelä, 1969; Adams, et al., 1970; Dequeker, 1972; Plato and Norris, 1980; Plato, Wood, et al., 1980; Kimura and Konishi, 1981; Ruff and Jones, 1981; Plato and Purifoy, 1982).
However, the cortical mass relative to the bone (MCI and $\mathrm{CA} / \mathrm{BA}$ ) and a biomechanical shape index (Imax/ Imin and BWmax/BWmin) are mostly identical in both hands. And also, no side-related differences are found in any parameters of bone density.

The left dominant specimen occurred in about $29 \%$ for CA in this series. This frequency is much greater than the occurrence of the lefthanded persons $(7.4 \%)$ in Japanese students investigated by Kimura and Konishi (1981). It probably suggests that the left metacarpals do not necessarily have wider cortices than the right in lefthanded individuals (Watson, 1973; Garn, et al., 1976; Kimura, 1980; Plato, Wood, et al., 1980; Kimura and Konishi, 1981).

The orientation of the principal major axis $(\theta)$ shows no side differences in both sexes. The major axis tilts radiad from the median line at its dorsal end on average of $16.9^{\circ}\left(18.0^{\circ}\right.$ in the right hand and $15.8^{\circ}$ in the left $)$ in males and of $7.2^{\circ}\left(6.0^{\circ}\right.$ and $\left.8.3^{\circ}\right)$ in females. The bone section is not completely circular but somewhat elliptical. Its shape index is about 1.2 and its biomechanical one is about 1.4 in both sexes. No relationships are found between the inclination of the major axis and deformation of the cross-section.

Atkinson and Weatherell (1967) reported that density is different between quadrants of the femoral shaft. In the present study, the radiogrametric parameter is generally greater in the dorsovolar direction than in the radioulnar in both sexes, except for $\mathrm{MCI}$. In microdensitometric parameters, the total pattern area (TPA) is greater in the dorsovolar direction than in the radioulnar, but the mean bone density (MBD) and the maximum/true bone density (MPH) are almost similar in two directions, in both sexes. The cortical thickness (CT), pattern area (PA) and bone density (BD) are greater at the ulnar side than the radial, and at the volar side than at the dorsal, in both sexes. However, the peak height $(\mathrm{PH})$ is almost similar at four sides. From these facts, it is estimated that the second metacarpal has more magnitude of bending rigidity in the dorsovolar direction than in the radioulnar, and more intensity against an external force on the volar side than on the dorsal and on the ulnar side than on the radial, respectively, and also, that such a laterality is not due to the difference of true bone density but only to that of bone and cortical mass at each side.

Total bone and cortical areas (BA and CA) and the second moments of area (Imax and Imin) are greater in the right hand than in the left in both sexes. Furthermore, it is noted that the greater BA and CA are in the right hand than in the left, the greater Imax and Imin are in the right hand. Therefore, it is suspected that there are some relationships for side-related differences between the second moments of area and the total and cortical bone areas. According to Ruff and Hayes $\left(1983^{2}\right)$, left lower limb bones (femur and tibia) are generally larger than right lower limb bones, with 
asymmetry being greater among females, for crosssectional biomechanical properties. In general, lower limbs present complicated side differences compared with upper limbs. Kimura and Asaeda (1974) suggested that, in the lower limb, the anti-handed side takes principally a supporting role and the handed a functional one.

The direction of asymmetry is individually characteristic for the majority of individuals, whether righthanded, lefthanded or ambidextrous (Garn, et al., 1976). The right hand generally presents greater values for parameters in general bone mass in the second metacarpal, but there are no side-related differences for parameters in relative cortical mass, bone shape and bone density. Biomechanical loadings may more-or-less act on the side-related differences of bone mass.

\section{Acknowledgements}

I wish to express my sincere thanks to Dr. Ronald Singer, Department of Anatomy, University of Chicago, for his kind advice in the preparation of the manuscript in English.

\section{References}

1) Adams, P., Davis, G.T. and Sweetnam, P.M.: Osteoporosis and the effects of aging on bone mass in elderly men and women. Quat. J. Med., 39: 601-615 (1970).

2) Aitken, J.M., Smith, C.B., Horton, P.W., Clark, D.L., Boyd, J.F. and Smith, D.A.: The interrelationships between bone mineral at different skeletal sites in male and female cadavers. J. Bone Joint Surg., 56-B2: 370-375 (1974).

3) Atkinson, P.J. and Weatherell, J.A.: Variation in the density of the femoral diaphysis with age. J. Bone Joint Surg., 49-B: 781-788 (1967).

4) Barnett, E. and Nordin, B.E.C.: The radiological diagnosis of osteoporosis: a new approach. Clin. Radiol., 11: 166-174 (1960).

5) Bloom, R.A.: A comparative estimation of the combined cortical thickness of various bone sites. Skeletal Radiol., 5: 167-170 (1980).

6) Dequeker, J.V.: Bone Loss in Normal and Pathological Conditions. Leuven Univ. Press, Leuven (1972).

7) Dequeker, J.V.: Quantitative radiology: radiogrametry of cortical bone. Brit. J. Radiol., 49: $912-920$ (1976).

8) Garn, S.M., Mayer, G.H. and Shaw, H.A.: Paradoxical bilateral asymmetry in bone size and bone mass in the hand. Am. J. Phys. Anthropol., 45: 209-210 (1976).

9) Horsman, A., Simpson, M. and Armes, F.: A left/right comparison of sequential bone loss from the metacarpal of postmenopausal women. Am. J. Phys. Anthropol., 54: 457-460 (1981).

10) Jungers, W.L. and Minns, R.J.: Computed tomography and biomechanical analysis of fossil long bones. Am. J. Phys. Anthropol., 19: 285-290 (1979).

11) Kimura, K.: Handedness and laterality of the extremities. Shinkei Kenkyu no Shinpo (Progress of Neurological Sciences), 24: 610-622 (1980) (in Japanese with English summary).

12) Kimura, K. and Asaeda, S.: On the morphological and functional laterality in human extremities, especially in the lower limb. J. Anthrop. Soc. Nippon, 82: 189-207 (1974) (in Japanese with English summary).

13) Kimura, K. and Konishi, M.: Handedness and laterality in some measurements of the human upper limb. Jpn. J. Health Hum. Ecol., 47: 51-61 (1981) (in Japanese with English summary).

14) Kimura, K., Konishi, M. and Kimura, K.: Side, age and sexrelated differences in microdensitometric measurements of the second metacarpal. Jpn. J. Hum. Posture, 9: 67-80 (1989).

15) Kimura, T.: Mechanical characteristics of human lower leg bones. J. Fac. Sci. Univ. Tokyo, Sect. 5, 4: 319-393 (1974).

16) Laval-Jeantet, A.-M., Goldman, S. and Laval-Jeantet, M.: Densitometrie osseuse de precision sur films sans ecrans. J. Radiol. Electrol., 58: 63-68 (1977).

17) Meema, H.E.: Cortical atrophy and osteoporosis as a manifestation of aging. Am. J. Roentgenol., 89: 1287-1295 (1963).

18) Montoye, H.J., McCabe, J.F., Metzner, H.L. and Garn, S.M.: Physical activity and bone density. Hum. Biol., 48: 599-610 (1976).

19) Nordin, B.E.C.: The definition and diagnosis of osteoporosis. Calcif. Tissue Int., 40: 57-58 (1987).

20) Plato, C.C. and Norris, A.H.: Bone measurements of the second metacarpal and grip strength. Hum. Biol., 52: 131-149 (1980).

21) Plato, C.C. and Purifoy, F.E.: Age, sex and bilateral variability in cortical bone loss and measurements of the second metacarpal. Growth, 46: 100-112 (1982).

22) Plato, C.C., Wood, J.L. and Norris, A.H.: Bilateral asymmetry in bone measurements of the hand and lateral hand dominance. Am. J. Phys. Anthropol., 52: 27-31 (1980).

23) Ruff, C.B. and Hayes, W.C.: Cross sectional geometry of Pecos Pueblo femora and tibiae - A biomechanical investigation: I. Method and general patterns of variation. Am. J. Phys. Anthropol., 60: 359-381 (1983)!.

24) Ruff, C.B. and Hayes, W.C.: Cross sectional geometry of Pecos Pueblo femora and tibiae - A biomechanical investigation: II. Sex, age, and side differences. Am. J. Phys. Anthropol., 60: 383-400 (1983) ${ }^{2}$.

25) Ruff, C.B. and Jones, H.H.: Bilateral asymmetry in cortical bone of the humerus and tibia - sex and age factors. Hum. Biol., 53: 69-86 (1981).

26) Saville, P.D., Heaney, R.P. and Pecker, R.R.: Radiogrametry at four bone sites in normal middle aged women. Their relation to each other, to calcium metabolism and to other biological variables. Clin. Orthop., 114: 307-315 (1976).

27) Virtama, P. and Helelä, T.: Radiographic measurements of cortical bone. Acta Radiol., Supp. 293: 1-268 (1969).

28) Virtama, P. and Mähönen, H.: Thickness of the cortical layer as an estimate of mineral content of human finger bones. Brit. J. Radiol., 33: 60-62 (1960).

29) Watson, R.C.: Bone growth and physical activity in young males. In: Mazess, R.B. (ed.), International Conference on Bone Mineral Measurement. U.S. Dept. HEW, U.S. Government Printing Office, Washington, D.C. (1973). 
Plate I
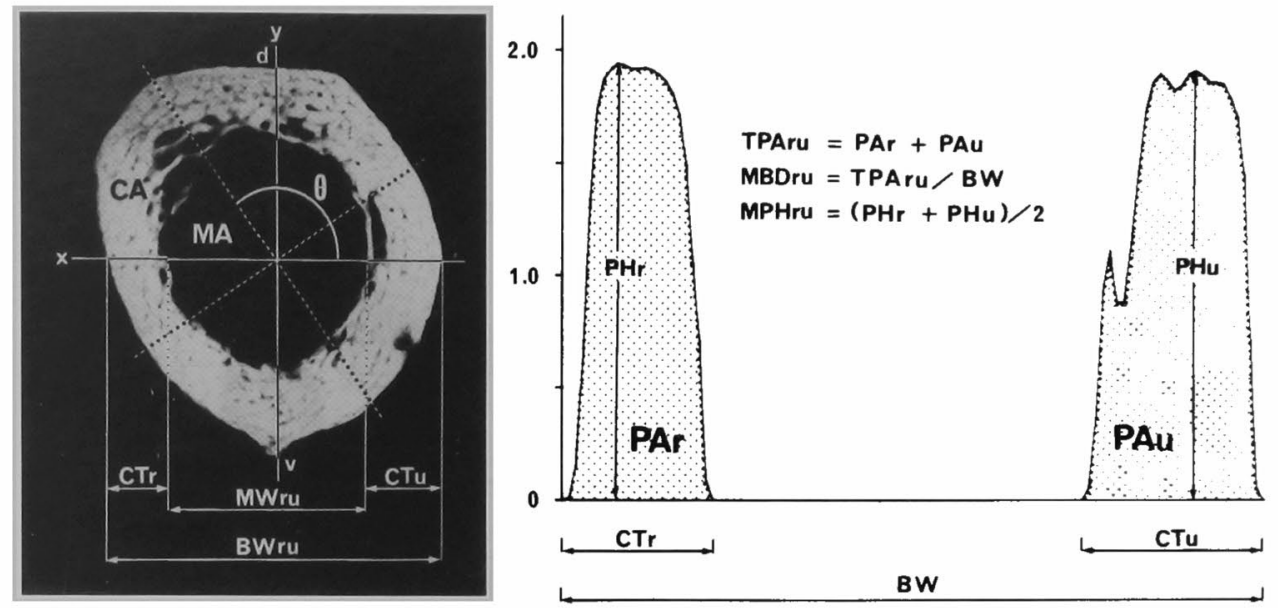

\section{Explanation of Figures}

\section{Plate I}

Fig. 1. Cross-sectional radiogrametry and microdensitometry in the second metacarpal of the right hand.

Abbreviations: In radiogrametry, BW, bone width (subperiosteal diameter); $\mathbf{M W}$, medullary width (subendosteal diameter); CCT combined cortical thickness (BW-MW); CT, cortical thickness; MCI, metacarpal cortical index (CCT/BW).

In biomechanical measurement, $\mathbf{B A}$, total bone area; MA, medullary area; CA, cortical area (BA-MA); CA/BA, relative cortical area; Imax, maximum second moment of area; Imin, minimum second moment of area; $\partial$, orientation of principal axis; Imax/Imin, biomechanical shape index; $\mathbf{B W} \mathbf{m a x} / \mathbf{B W m i n}$, morphological shape index.

In microdensitometry, PA, pattern area; TPA, total pattern area (total bone density [TBD]); BD, standardized bone density (PA/BW); MBD, standardized mean bone density (TPA/BW); PH, pattern peak height; MPH, mean pattern peak height (maximum bone density [MaxBD]). 